\title{
Effect of Total Pressure and Furnace Tube Material on the Oxidation of T22 in Humidified Air
}

\author{
Clara Schlereth $^{1}$ (D) - Mathias C. Galetz ${ }^{1}$
}

Received: 26 May 2021 / Revised: 26 May 2021 / Accepted: 27 May 2021 /

Published online: 8 June 2021

(c) The Author(s) 2021

\begin{abstract}
Oxidation of the Fe-base alloy T22 in humid air at $500{ }^{\circ} \mathrm{C}$ was investigated. The samples were exposed for up to $1000 \mathrm{~h}$ at $1 \mathrm{bar}$ and $20 \mathrm{bar}$. The influence of three furnace tube materials, alumina, ET45 and quartz glass, on the oxide scale morphology was investigated. Samples and their cross sections were examined using optical microscopy, scanning electron microscopy, electron probe micro analysis and Raman spectroscopy. Multilayered oxide scales consisting of hematite, magnetite and $\mathrm{Fe}-\mathrm{Cr}$ spinel were found on all samples. However, the composition and morphology of the oxide scales depend on the furnace tube material and on the system pressure. The system pressure is assumed to change the reaction equilibria and adsorption rates. The tube material changed the initial gas composition by formation of volatile $\mathrm{Cr}$ species. This volatilization rate increased at higher system pressures.
\end{abstract}

Keywords Water vapor · Pressure $\cdot$ Volatilization · Oxide morphology $\cdot$ Low alloyed steel

\section{Introduction}

High temperature oxidation by gases with varying water vapor contents occurs e.g., in power generation or in the petrochemical industry [1]. In these applications, tubes and parts are often made of Fe-base alloys. When exposed to oxidizing environments, these alloys form $\mathrm{Cr}$ - and/or Fe-containing oxides. When the $\mathrm{Cr}$ content in the alloy is high enough to form a continuous chromia $\left(\mathrm{Cr}_{2} \mathrm{O}_{3}\right)$ scale, the oxidation rate is low due to the slow growth rate of chromia. However, the chromia scale stability is reduced in atmospheres with water vapor and on alloys with low $\mathrm{Cr}$

Clara Schlereth

clara.schlereth@dechema.de

Mathias C. Galetz

mathias.galetz@dechema.de

1 DECHEMA-Forschungsinstitut, Theodor-Heuss-Allee 25, 60486 Frankfurt am Main, Germany 
content $[1,2]$. In Fe oxide-rich scales, usually a hematite $\left(\mathrm{Fe}_{2} \mathrm{O}_{3}\right)$ layer is formed at the scale/gas interface and magnetite $\left(\mathrm{Fe}_{3} \mathrm{O}_{4}\right)$ is formed underneath, both as outward growing oxides. Below the original alloy surface, $\mathrm{Fe}-\mathrm{Cr}$-spinel can form and a chromia scale may be present between the spinel and the alloy or an internal oxidation zone $[1,3,4]$.

In oxidizing environments, the formation of hematite crystals in the form of whiskers or platelets on top of the scale is often observed. It is assumed that either the surface diffusion or the dissociation of the oxidant is the rate-limiting step for platelet formation. Hence, the rapid dissociation of water enhances the formation of oxide platelets $[5,6]$.

The formation of volatile (oxy-)hydroxides is another important aspect responsible for mass loss of the samples in water vapor-containing atmospheres at high temperatures. Two compounds which usually form on $\mathrm{Fe}-\mathrm{Cr}$ alloys are $\mathrm{CrO}_{2}(\mathrm{OH})_{2}$ and $\mathrm{Fe}(\mathrm{OH})_{2}$ [7]. According to data compiled by Meschter et al. [7] the vapor pressure of $\mathrm{CrO}_{2}(\mathrm{OH})_{2}$ at $600{ }^{\circ} \mathrm{C}$ is $2.0 \times 10^{-6}$ bar in an atmosphere with 1.0 bar $\mathrm{H}_{2} \mathrm{O}$ and 0.5 bar $\mathrm{O}_{2}$. The partial pressure of $\mathrm{Fe}(\mathrm{OH})_{2}$ in the same environment is calculated as $7.1 \times 10^{-15}$ bar. Alumina and silica are often present in the form of tubes or crucibles of high temperature testing devices. In the described condition, they form the volatile species $\mathrm{Al}(\mathrm{OH})_{3}$ and $\mathrm{Si}(\mathrm{OH})_{4}$ with $3.9 \times 10^{-12}$ and $1.6 \times 10^{-7}$ bar partial pressure, respectively. When a species has a partial pressure of more than $10^{-9}$ to $10^{-4}$ bar, measurable material loss is expected, depending on the respective reaction kinetics [8-10]. Thus, the formation of $\mathrm{CrO}_{2}(\mathrm{OH})_{2}$ needs to be considered for $\mathrm{Fe}-\mathrm{Cr}$-alloys as it might increase the depletion of $\mathrm{Cr}$ from the sub-surface of the material. The formation of $\mathrm{Fe}(\mathrm{OH})_{2}$ or $\mathrm{Al}(\mathrm{OH})_{3}$ can be neglected at $600{ }^{\circ} \mathrm{C}$ and below, while the formation of $\mathrm{Si}(\mathrm{OH})_{4}$ should also be considered e.g., in quartz glass reaction tubes.

Typical materials used for furnace tubes are quartz glass and alumina $\left(\mathrm{Al}_{2} \mathrm{O}_{3}\right)$. In most studies, the influence of the tube material on the gas atmosphere is neglected. Opila [11] showed that impurities in high-purity alumina tubes can enhance the oxidation rate of $\mathrm{SiC}$ at $1300{ }^{\circ} \mathrm{C}$. Also, mass spectrometry of the exhaust gas of exposure tests of $\mathrm{Cr}, \mathrm{Al}, \mathrm{Si}$, and their oxides showed that volatile species containing these elements are formed at $650{ }^{\circ} \mathrm{C}$ and 1 atm in humidified argon [12]. Hence, the gas atmosphere that comes in contact with the sample may contain volatile species from a prior reaction with the furnace tube. In this study, exposure tests in different tubes are compared to evaluate the influence of the tube material on the oxidation characteristics of the samples.

Another aspect which is looked at here is the total system pressure. Processes and process efficiency often require elevated system pressure. The influence of elevated pressure is neglected in most laboratory studies due to the complexity of a high pressure testing device. However, from the thermodynamic point of view, changes in pressure are expected to shift the equilibria of reactions between gases and solids $[13,14]$. In addition, the adsorption behavior of the gas is pressure-dependent [15]. In terms of kinetics, increased collision frequency between gas molecules and the sample are expected [14]. Studies at elevated pressure showed changes in the high temperature corrosion behavior, as reported e.g., for dry air [16], supercritical $\mathrm{CO}_{2}$ [17-21] or carburizing atmospheres [14, 22]. 
Corrosion issues in steam turbines have initiated research on water vapor-induced oxidation at elevated pressure in static or flowing pure steam [17, 23-28]. In these studies, Fe- and Ni-base alloys were tested. Other studies at elevated pressure have been performed on $\mathrm{SiC}[29,30]$. In some of the mentioned work, an increase in oxide scale growth at elevated pressure was found [17, 24, 27, 28], while other studies found similar or enhanced oxide scale growth at atmospheric pressure [23, $25,26]$. A possible explanation for enhanced scale growth at elevated pressure is an increase of diffusion rates in the oxide and alloy [24, 28, 31]. However, when the stresses caused by the applied pressure are high enough to induce lattice defects such as dislocations, simple compression of the crystal lattice reduces the diffusion rates in most metals [32]. Therefore, the increase in diffusion rate has to be mainly related to the changes in the gas phase.

According to calculations performed by Holcomb [24], an increase in solid state diffusion alone is not sufficient to explain the observed changes in the oxide scale at elevated pressure. Other factors attributing to the different oxidation behavior may be the increase in scale porosity [33] or the dissolution of impurities [34]. The detailed mechanism behind this phenomenon has not been fully understood yet.

The aim of this study is to evaluate the influence of the tube material and system pressure on the oxidation of a low alloyed steel (T22) at $500{ }^{\circ} \mathrm{C}$ in humid air. T22 was chosen because it forms a relatively thick multilayered oxide scale allowing a detailed examination of the scale.

\section{Experimental Procedures}

The chemical composition of T22 is given in Table 1.

Sample coupons with the dimensions $15 \times 10 \mathrm{~mm}$ were cut from a T22 plate and ground to a P1200 grit finish. Two samples were exposed under each condition. The samples were put in separate alumina crucibles. The tests were performed at $500{ }^{\circ} \mathrm{C}$ for $310 \mathrm{~h}, 690 \mathrm{~h}$ and $1000 \mathrm{~h}$ by discontinuous isothermal testing. The gas mixture was synthetic air with 7.6 vol\% water vapor at 20 bar and synthetic air with $10 \mathrm{vol} \%$ water vapor at atmospheric pressure. This difference in the water vapor content resulted from a variation in the actual, determined dosage.

To evaluate the influence of gases formed by possible reactions with alumina, chromia or silica, the tests were performed in three kinds of furnace tubes. Tests at both pressures were performed in high-purity alumina tubes and in preoxidized tubes made of Centralloy ET45 micro (named ET45 in the following). ET45 is a Nibase alloy containing $35 \mathrm{wt} \% \mathrm{Cr}$ and $16 \mathrm{wt} \% \mathrm{Fe}$ and thus a chromia-forming alloy. Exposure in a quartz glass tube was performed only at atmospheric pressure.

Table 1 Chemical composition of T22

\begin{tabular}{lllllllllll}
\hline & $\mathrm{Fe}$ & $\mathrm{C}$ & $\mathrm{Si}$ & $\mathrm{Mn}$ & $\mathrm{P}$ & $\mathrm{S}$ & $\mathrm{Cr}$ & $\mathrm{Mo}$ & $\mathrm{Cu}$ & $\mathrm{N}$ \\
\hline In wt\% & Rest & $0.08-0.14$ & $\leq 0.35$ & $0.40-0.80$ & $\leq 0.02$ & $\leq 0.01$ & $2.0-2.5$ & $0.9-1.10$ & $\leq 0.30$ & $\leq 0.012$ \\
\hline
\end{tabular}


All exposure tests were conducted in a horizontal furnace in flowing gas. For the tests at atmospheric pressure, heated distilled water was pumped along a membrane to enrich the gas with water vapor. Heating and cooling of the furnace were carried out in a dry atmosphere to avoid condensation in the furnace. The gas flow rates used in the different exposure tests are given in Table 2. A total gas flow rate of $6 \mathrm{ln} / \mathrm{h}$ (norm liter per hour) was set in all cases. Different diameters of the furnace tubes and reduced gas flow at elevated pressure caused the differences in gas flow rates at the samples.

In the tests at elevated pressure, a mass flow controller regulated the supply of synthetic air. When the exposure temperature was reached, water vapor was added to the gas flow by feeding distilled and degassed water to the gas at the target pressure. The mixture was heated to evaporate the water and led into the furnace. A pressure controller was positioned behind the condenser at the gas exit of the furnace. The pressure was increased or decreased simultaneously to the heating or cooling of the furnace, respectively. For the test at elevated pressure with alumina tube, the alumina tube was inserted into the high-pressure rack. With this arrangement it was ensured that the heated gas only came in contact with the alumina tube before reaching the sample.

Mass changes of the samples before and after exposure were recorded using a precision $(0.01 \mathrm{mg}$ ) weighing balance (Mettler Toledo). Cross sections of samples were prepared using conventional metallographic methods involving nickel plating, hot mounting in resin, grinding with $\mathrm{SiC}$ papers and polishing with diamond suspension $(1 \mu \mathrm{m})$. Analysis was performed using optical microscopy, scanning electron microscopy (SEM, Hitachi FlexSEM 1000) and electron probe microanalysis (EPMA, Jeol JXA-8100). Raman spectroscopy (Renishaw inVia Raman Microscope) with a laser wavelength of $633 \mathrm{~nm}$ was used to analyze the oxide phases.

\section{Results}

The mass gain of the samples over exposure time is given in Fig. 1a. Two samples were weighed for each data point and the mean value and deviations are plotted. A higher mass gain was found for the samples exposed at 1 bar. When comparing the tube material, samples exposed in the ET45 tube showed the highest mass gain. The mass gain in the quartz tube was the lowest for the exposures at 1 bar. In general, mass gains in the same order of magnitude were recorded.

Cross sections of the samples are shown in Fig. 2. The bright layer on top of the oxide is a nickel plating to protect the oxide scales during preparation. Three layers formed under all tested conditions: A hematite layer (light gray), a porous magnetite layer (dark gray) and a dense inner oxide layer (dark gray, below the dashed line). Hematite formed around some of the pores on all samples. A major difference between the

Table 2 Gas flow rates in the different exposures

\begin{tabular}{llllll}
\hline Pressure & 1 bar & & \multicolumn{3}{c}{20 bar } \\
\hline Tube & Alumina & ET45 & Quartz glass & Alumina & ET45 \\
$\begin{array}{c}\text { Flow rate } / \mathrm{cm} / \\
\text { min }\end{array}$ & 5.7 & 9.5 & 5.4 & 1.0 & 0.51 \\
\hline
\end{tabular}



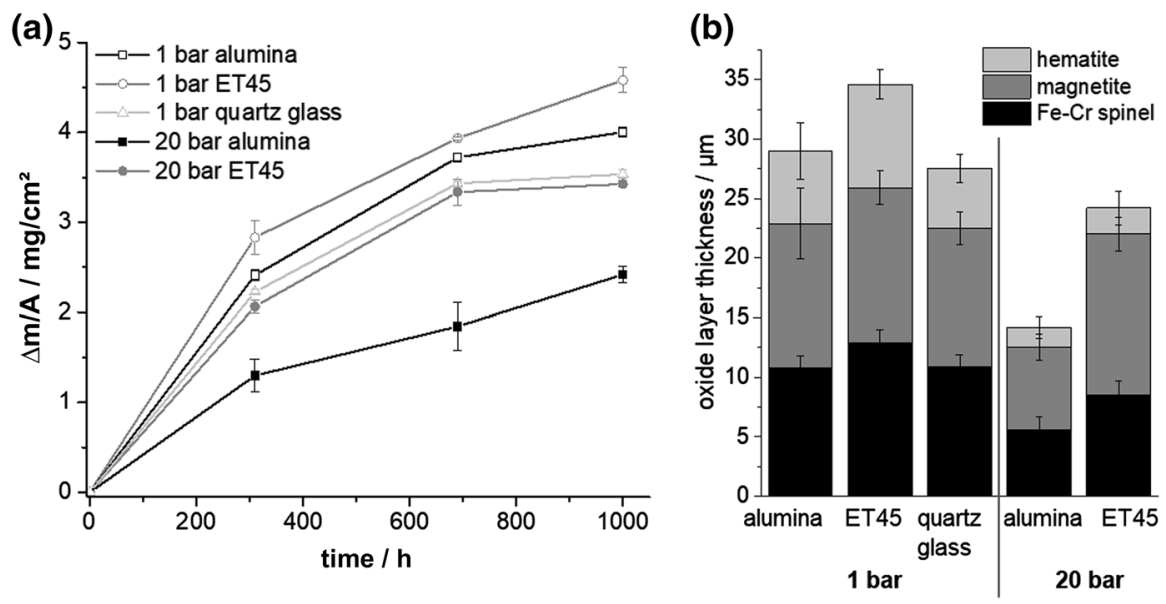

Fig. 1 a Mean mass gain of the samples; b oxide layer thicknesses of the samples exposed for $1000 \mathrm{~h}$

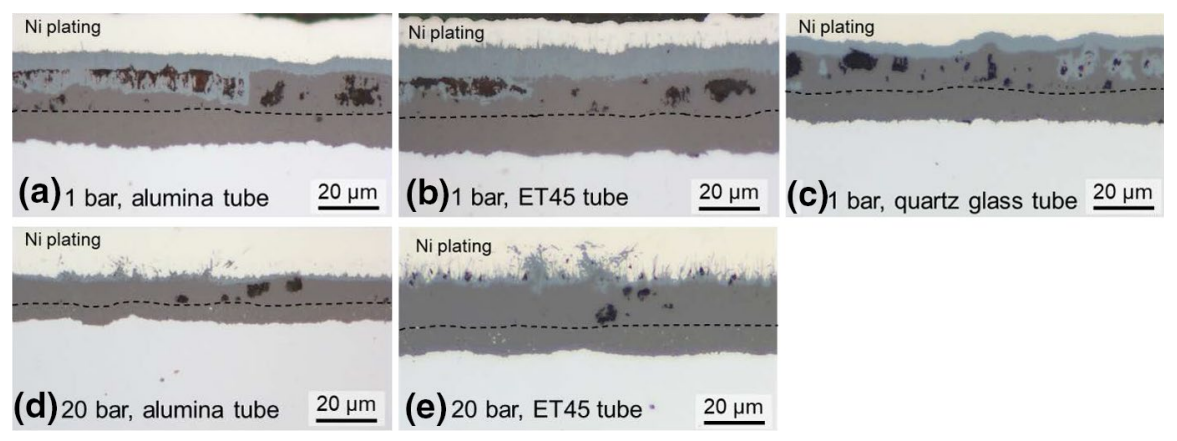

Fig. 2 Optical microscopy images of sample cross sections after $1000 \mathrm{~h}$ exposure a at 1 bar in an alumina tube, $\mathbf{b}$ at 1 bar in an ET45 tube, $\mathbf{c}$ at 1 bar in a quartz glass tube, $\mathbf{d}$ at 20 bar in an alumina tube, and $\mathbf{e}$ at 20 bar in an ET45 tube. The dashed lines indicate the position of the original metal surface

samples exposed at 1 and 20 bar is the thickness of the hematite layer. For a quantitative comparison, the oxide layer thicknesses were measured with the semi-automated software Layers by GFaI e.V. and plotted in Fig. 1b. A thinner hematite layer formed on the samples exposed at 20 bar. The oxide scale thickness and layer distribution on the samples exposed at 1 bar are similar for all tube materials.

The surface of the samples was examined with SEM. Oxide platelets formed on all samples, as shown in Fig. 3 for the samples exposed for $1000 \mathrm{~h}$. The smallest platelets were found on the samples exposed in the alumina tube at 1 bar, while the largest platelets grew on the samples exposed in the ET45 tube at 20 bar. This can also be seen in the cross sections (Fig. 2e). After shorter exposure times, similar morphologies formed on the samples exposed in the alumina and ET45 tubes (not shown). Only the platelet structure on the sample exposed in the quartz glass tube at 1 bar changed in the investigated time. These samples formed small, separated 

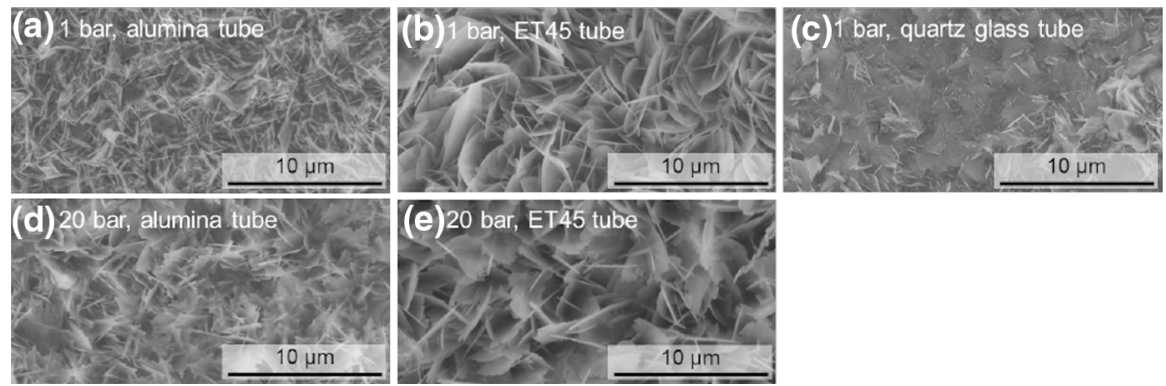

Fig. 3 SEM surface images of samples after $1000 \mathrm{~h}$ exposure, $\mathbf{a}$ at 1 bar in an alumina tube, $\mathbf{b}$ at 1 bar in an ET45 tube, $\mathbf{c}$ at 1 bar in a quartz glass tube, $\mathbf{d}$ at 20 bar in an alumina tube, and $\mathbf{e}$ at 20 bar in an ET45 tube

platelets during the first $690 \mathrm{~h}$ of exposure. After $1000 \mathrm{~h}$, the density of the platelets increased, as shown in Fig. 3c.

EPMA measurements were performed on the cross sections of the samples exposed for $1000 \mathrm{~h}$. As expected, the oxide scales consist mainly of Fe oxides. The distribution of most elements is similar in the oxide scale of all samples. Minor amounts of around $0.4 \mathrm{wt} \% \mathrm{Mn}$ were found in the inner and outer oxide scale. In the inner scale, $\mathrm{Si}$ (around $0.3 \mathrm{wt} \%$ ), $\mathrm{Cu}$ (around $0.3 \mathrm{wt} \%$ ), Mo (around $2 \mathrm{wt} \%$ ) and $\mathrm{Al}$ (less than $0.1 \mathrm{wt} \%$ ) were detected as well. Interestingly, the $\mathrm{Cr}$ distribution in the scale differs depending on the furnace tube and pressure. Line scans with $0.3 \mu \mathrm{m}$ steps were obtained from each sample to investigate the average distribution of $\mathrm{Cr}$ in the scale. The formation of hematite and magnetite in the outward-grown scale was confirmed. The inward-grown scale is a (Fe, $\mathrm{Cr})$-spinel.

The inner oxide scale contains roughly 3-4 wt\% $\mathrm{Cr}$ in all samples. A direct comparison between the $\mathrm{Cr}$ distribution in the outer scale of the samples after exposure for $1000 \mathrm{~h}$ is given in Fig. 4. Three different types of behavior can be differentiated for the $\mathrm{Cr}$ distribution in the outer scale. First, the samples exposed in the alumina or quartz glass tube at 1 bar (Fig. $4 \mathrm{a}, \mathrm{c}$ ) have a $\mathrm{Cr}$ gradient in the outer scale from 0.3 $\mathrm{wt} \%$ at the interface between the inner and outer scale to negligible amounts at the scale/gas interface. Secondly, the samples exposed at 20 bar in the alumina tube and at 1 bar in the ET45 tube (Fig. 4b, d) show slight Cr enrichments of $0.15-0.30 \mathrm{wt} \%$ $\mathrm{Cr}$ in the outer scale, with a maximum in the outer part of the scale. No correlation between the $\mathrm{Cr}$ distribution and the oxide phases (hematite and magnetite) is found. The third kind of $\mathrm{Cr}$ distribution is observed on the samples exposed in the ET45 tube at 20 bar (Fig. 4e). The $1000 \mathrm{~h}$ sample shows the highest amount of $\mathrm{Cr}$ in the outer oxide scale of up to $2 \mathrm{wt} \%$.

On the three samples that showed $\mathrm{Cr}$ enrichment in the outer scale, the $\mathrm{Cr}$ distribution in the outer scale after $310 \mathrm{~h}$ was measured as well. On the samples exposed in the ET45 tube, low amount of chromium in the outer oxide scale is found in the zone near the original metal surface. The region near the gas/scale interface is enriched with $\mathrm{Cr}$. On the samples exposed at elevated pressure, the amount of $\mathrm{Cr}$ increased from 310 to $1000 \mathrm{~h}$. The sample exposed at 1 bar in the ET45 tube has a slightly higher amount of $\mathrm{Cr}$ in the outer scale after $310 \mathrm{~h}$ than after $1000 \mathrm{~h}$. 


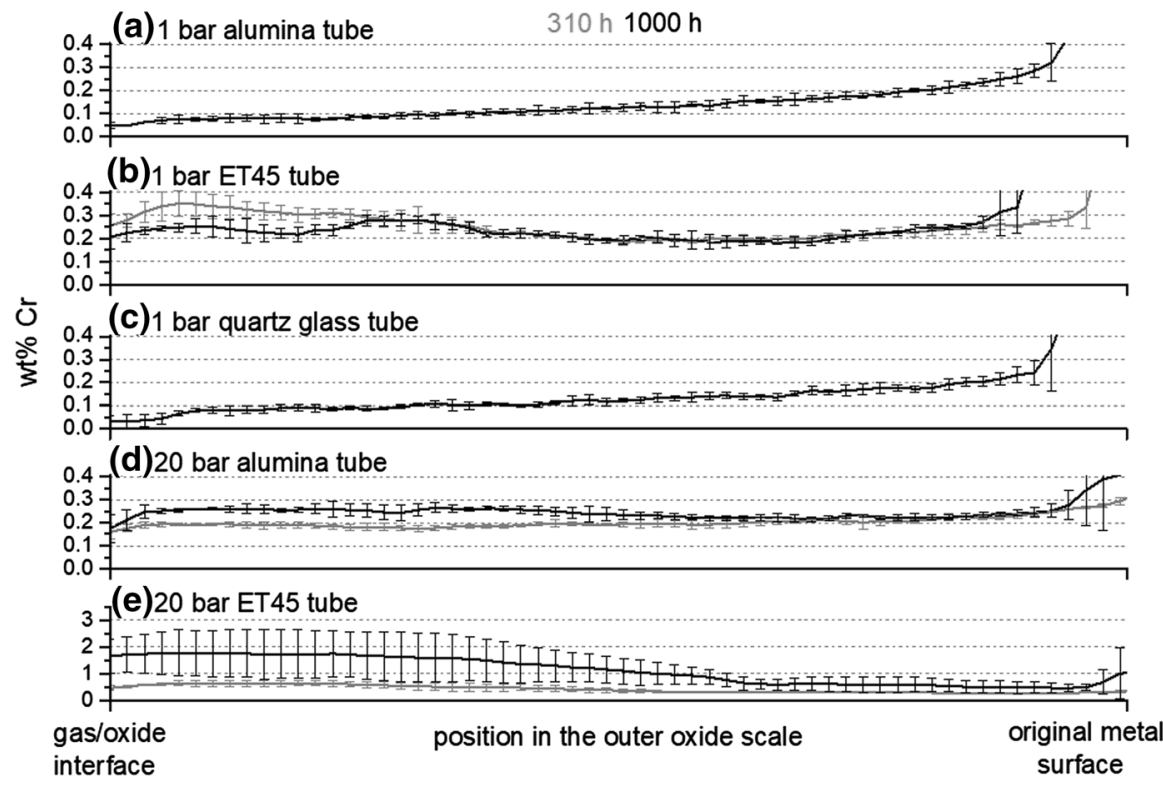

Fig. $4 \mathrm{Cr}$ line scans of all samples in the outer scale after $1000 \mathrm{~h}$ and additionally after $310 \mathrm{~h}$ for samples that show $\mathrm{Cr}$ enrichment. Four line scans were averaged and normalized across the oxide scale for each curve in the diagram. The gas/oxide interface is located at the left side of the diagram and the original metal surface at the right side. The vertical lines represent the standard deviation of the data. Note the different scale of the $y$ axis in $\mathbf{e}$

Raman spectroscopy was used to confirm the phases in the oxide scale. Line scans along the oxide scales were obtained from the cross sections.

In the Raman spectra of the outer magnetite and inner $\mathrm{Fe}-\mathrm{Cr}$ spinel layer (not shown), the peak at Raman shift around $674 \mathrm{~cm}^{-1}$ is correlated with the $(\mathrm{Fe}, \mathrm{Cr})_{3} \mathrm{O}_{4}$ structure [35]. Chromia is not detected on any sample after $1000 \mathrm{~h}$. In Fig. 5, the Raman spectra of the hematite layer of the samples exposed for $1000 \mathrm{~h}$ are shown. Raman measurements of all samples confirm hematite by peaks at 228, 246, 294, 413, 500, 615 and $1322 \mathrm{~cm}^{-1}$, which are in good correlation to the values given by Ohtsuka et al. [36]. Only the sample exposed at 20 bar in the ET45 tube shows a slightly different spectrum. For this sample (which has around $2 \mathrm{wt} \% \mathrm{Cr}$ in hematite and magnetite, see Fig. 4), an additional peak at $660 \mathrm{~cm}^{-1}$ is found. McCarty and Boehme [35] performed a study of the influence of the solid solution compositions $\mathrm{Fe}_{3-\mathrm{x}} \mathrm{Cr}_{\mathrm{x}} \mathrm{O}_{4}$ and $\mathrm{Fe}_{2-\mathrm{x}} \mathrm{Cr}_{\mathrm{x}} \mathrm{O}_{3}$ on the Raman signal and reported that an additional peak at $664 \mathrm{~cm}^{-1}$ appears in the Raman spectrum when $(\mathrm{Fe}, \mathrm{Cr})_{2} \mathrm{O}_{3}$ contains $9.7 \mathrm{wt} \% \mathrm{Cr}$. Hence, the additional peak at $660 \mathrm{~cm}^{-1}$ indicates formation of $(\mathrm{Fe}, \mathrm{Cr})_{2} \mathrm{O}_{3}$ instead of hematite. 


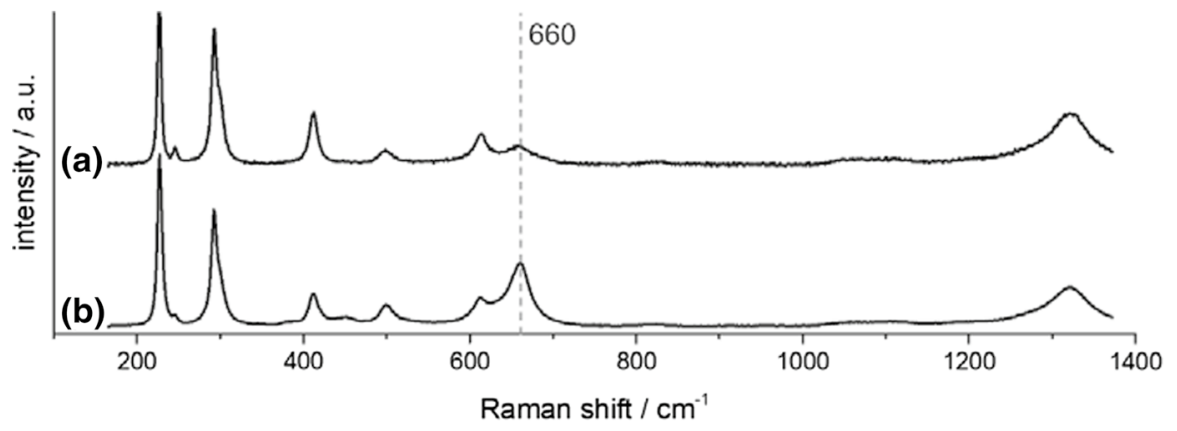

Fig. 5 Raman spectra of the hematite layer in the outer oxide scale, obtained from cross sections of samples exposed for $1000 \mathrm{~h}$ a representative spectrum of all hematite layers formed at 1 bar and the hematite layer formed at 20 bar in an alumina tube, b spectrum of the hematite layer formed at 20 bar in the ET45 tube

\section{Discussion}

Previous studies have reported a breakaway effect for water vapor oxidation for 9 $\mathrm{wt} \% \mathrm{Cr}$ steel $[3,37]$. While thin chromia scales formed in atmospheres with no or low amounts of water vapor, faster growing iron-rich oxide scales formed at higher amounts of water vapor due to enhanced Cr-depletion. After breakaway similarly thick iron-rich scales are found as observed here. In our exposures, slightly thicker oxide scales formed in $10 \%$ water vapor at atmospheric pressure compared to scales formed in $7.6 \%$ at elevated pressure. Pores are found in the outer scale of all samples. The reason for this faster diffusion behavior in the presence of $\mathrm{H}_{2} \mathrm{O}$ can be explained by two approaches, both centered around the hypothesis that during oxidation, the adsorbed water dissociates more rapidly than oxygen and a high concentration of $\mathrm{OH}^{-}$is expected to build up in the scale [1]: (1) To maintain the net charge in the oxide, additional metal cation vacancies are formed [1], which facilitates outward diffusion of the metal ions and the oxide grows faster. (2) Vacancies accumulate and form pores in the scale, a typical phenomenon for water vapor oxidation $[38,39]$. According to the mechanism described by Rahmel and Tobolski [39], the pores contain $\mathrm{H}_{2}$ and $\mathrm{H}_{2} \mathrm{O}$. Continuous reduction and oxidation of the gas in the pores play an important role in the inward transport of oxygen in the scale.

Inner and outer oxide scales formed on all samples, which means that both inward diffusion of the oxidant and outward diffusion of metal cations contributed to scale growth. The relation between the thickness of the outer and inner scale depends on the respective diffusion rates. The relation varies between 1.5 and 1.9 for the investigated samples (see Table 3). No clear trend can be seen. The thickness of the hematite layer of the samples exposed at 20 bar is about half of that formed at 1 bar, see Table 3. Zurek et al. [40] and Segerdahl et al. [41] showed that accumulation of hydrogen at the surface can lower or inhibit hematite formation. In both studies, the hydrogen produced from the oxidation by water vapor accumulated due to low gas flow rates. In the present study, the gas flow rates vary from 0.51 to $9.5 \mathrm{~cm} /$ min depending on the tube diameter and total pressure of the exposure tests (see 
Table 3 Rheological parameter in the different exposure tests and oxide layer relations of the respective samples

\begin{tabular}{llllll}
\hline Pressure & 1 bar & & \multicolumn{3}{c}{20 bar } \\
\hline Tube & Alumina & ET45 & Quartz glass & Alumina & ET45 \\
$\begin{array}{c}\text { Outer/inner } \\
\text { scale ratio } \\
\text { after 1000 h }\end{array}$ & 1.7 & 1.7 & 1.5 & 1.5 & 1.9 \\
$\begin{array}{c}\text { Hematite/total } \\
\text { oxide scale } \\
\text { ratio after }\end{array}$ & 0.21 & 0.25 & 0.18 & 0.12 & 0.09 \\
$\begin{array}{l}1000 \mathrm{~h} \\
\mathrm{Re}^{0.5} \mathrm{Sc}^{0.343}\end{array}$ & 0.51 & 0.66 & 0.50 & 0.96 & 0.68 \\
\hline
\end{tabular}

Table 2). However, gas exchange rates above the surface depend not only on the gas flow rate, but also on the gas composition, total pressure and temperature. According to Holcomb [24, 42], the rate of newly formed hydrogen flux from the sample surface is proportional to the product $\mathrm{Re}^{0.5} \mathrm{Sc}^{0.343}$ with the Reynolds number Re and the Schmidt number Sc. This value of the tested conditions is given in Table 3. The flux rate of hydrogen from the surface is higher in the exposure tests at 20 bar than at 1 bar. The values are similar for exposure tests in the ET45 tube at both pressures. If hydrogen accumulation due to lower flux rates would be responsible for the differences in hematite layer thickness, thinner hematite layers would be expected at the samples exposed at atmospheric pressure. However, the contrary is the case, meaning that in this study, the varying gas flow rates are not decisive for the differences in the hematite layers.

Excluding changes in diffusion and gas depletion, the decreased hematite thickness at elevated pressure could be connected with a change in the phase stabilities. In other studies at elevated pressures, enhanced formation of spinels in outer oxide scales was reported [14, 24, 31]. Here, the enhanced formation of magnetite, which has a spinel structure, shows a similar trend. According to the EPMA measurements, the elements in the outer oxide scale are oxygen, $\mathrm{Fe}$, low amounts of $\mathrm{Mn}$ and different amounts of Cr. Raman spectra show that only two phases formed in the scale of all samples: the corundum structure $\mathrm{Fe}_{2} \mathrm{O}_{3}$ and the spinel structure $(\mathrm{Fe}, \mathrm{Cr})_{3} \mathrm{O}_{4}$. The sample oxidized at 20 bar in the ET45 tube additionally showed a peak at $660 \mathrm{~cm}^{-1}$ which stems from ( $\mathrm{Fe}, \mathrm{Cr})_{2} \mathrm{O}_{3}$ according to [35]. In the outer scale of the samples exposed at 1 bar in the ET45 tube and at 20 bar in the alumina tube, only $0.3 \mathrm{wt} \% \mathrm{Cr}$ is dissolved. In the hematite layer on these samples no additional peak is detected.

In the tested conditions, formation of volatile species from the furnace tube, from alumina crucibles and from samples is possible. In a study by Pérez-Trujillo et al. [12], formation of volatile species over chromia, Fe, alumina and silica during exposure in $\mathrm{Ar}$ with $80 \% \mathrm{H}_{2} \mathrm{O}$ at $650{ }^{\circ} \mathrm{C}$ were detected. These species are formed by reaction of the metal or oxides with oxygen and water vapor. When passing through a cooler part of the furnace, the volatile species can deposit on the tube walls. The collection of condensate is often used to quantify formation of $\mathrm{Cr}$-containing volatile species [43]. When different materials are present in the hot zone of the furnace, volatile species can form from one material and deposit on the other, if the activity 
of the element is high in one and low in the other material. This mechanism is for example observed in solid oxide fuel cells. Here, volatile $\mathrm{Cr}$ species can form at the interconnects and accumulate on the cathode. Even though the effect has been studied intensively, the mechanism of $\mathrm{Cr}$ deposition is still under discussion [44, 45].

In the presented results, the formation and deposition of volatile Cr-containing species play an important role. Due to the low temperatures and presence of water vapor, $\mathrm{CrO}_{2}(\mathrm{OH})_{2}$ is assumed to be the major volatile $\mathrm{Cr}$ species present. It forms by reaction of chromia with oxygen and water vapor [13]:

$$
\frac{1}{2} \mathrm{Cr}_{2} \mathrm{O}_{3}(\mathrm{~s})+\frac{3}{4} \mathrm{O}_{2}(\mathrm{~g})+\mathrm{H}_{2} \mathrm{O}(\mathrm{g}) \leftrightarrow \mathrm{CrO}_{2}(\mathrm{OH})_{2}(\mathrm{~g})
$$

The tube material ET45 has a high Cr content of $35 \mathrm{wt} \%$ and is expected to form a chromia scale at the surface in oxidizing conditions. Hence, enrichment of the gas with $\mathrm{CrO}_{2}(\mathrm{OH})_{2}$ in the ET45 tube can be expected. The T22 samples exposed at 1 bar in the alumina and quartz glass tube form a Fe oxide scale with negligible amounts of $\mathrm{Cr}$ at the scale/gas interface. Here, only low amounts of $\mathrm{CrO}_{2}(\mathrm{OH})_{2}$ are expected to derive from the T22 samples. In the ET45 tube, when the $\mathrm{Cr}$ activity in the gas is higher than at the oxide surface, $\mathrm{CrO}_{2}(\mathrm{OH})_{2}$ adsorbs. The low $\mathrm{Cr}$ activity of iron oxide then allows incorporation of $\mathrm{Cr}$ into the outer scale of the samples. The continuous condensation of $\mathrm{Cr}$ during the exposure is manifest as the higher amount of $\mathrm{Cr}$ in the outward-growing oxide scale. The outer scale of the samples exposed at 20 bar in the ET45 tube contains ten times more $\mathrm{Cr}$ than the samples exposed at 1 bar. This can be ascribed to several changes in the gas due to elevated pressure. Firstly, the adsorption and surface coverage with gas molecules is expected to increase at higher pressure, according to the Langmuir adsorption model [15]. In addition, the reaction equilibria are shifted to the side with lower amounts of gas molecules according to Le Chateliers' principle. This implies an increased formation of $\mathrm{CrO}_{2}(\mathrm{OH})_{2}$. Calculations of the thermodynamic equilibrium of the gas with the software Factsage confirm that the partial pressure of $\mathrm{CrO}_{2}(\mathrm{OH})_{2}$ in the gas over ET45 increases from 1 to 20 bar by two orders of magnitude. Hence, more $\mathrm{Cr}$ is deposited on the sample.

Interestingly, the sample exposed at 20 bar in the alumina tube has a similar amount of $\mathrm{Cr}$ in the outer oxide scale as the sample exposed at 1 bar in the ET45 tube, but the slope is different and does not show an enrichment toward the surface. Thus, while the origin of $\mathrm{Cr}$ on the latter can be ascribed to be the ET45 furnace tube, another mechanism has to be pressure-related that might also be responsible for the slower growth rates at 20 bar. Since the only source of $\mathrm{Cr}$ is the T22 sample itself with around $2.25 \mathrm{wt} \%$, an increased formation of $\mathrm{CrO}_{2}(\mathrm{OH})_{2}$ by elevated pressure has also to be considered. In case the scale was not dense, the volatile compound could form from the spinel in the inner oxide layer, diffuse outward through pores and distribute in the scale. Alternatively, changes in the phase stability toward a spinel structure in the outer scale as mentioned above may also enhance the outward diffusion of $\mathrm{Cr}$.

The samples exposed at 1 bar showed different surface morphologies depending on the furnace tube. In all conditions, the formation of oxide platelets was 
observed. The size and density of platelets varies, larger platelets were found on samples exposed in the ET45 tube, while dense structures were found on the samples exposed in the quartz glass tube for $1000 \mathrm{~h}$. The increased platelet growth in the ET45 tube compared to the others may be connected with higher amounts of $\mathrm{CrO}_{2}(\mathrm{OH})_{2}$. The reason for different morphologies on samples exposed in the quartz glass or alumina tube is unsure. Opila [11] showed that high-purity alumina tubes may contain impurities in the ppm range that influence the scale growth. This amount is below the detection limit of EPMA. Further studies are needed to clarify the cause of different surface morphologies. These results indicate that direct comparison of Fe-oxide scales formed in alumina and quartz glass tubes in humid environment can be inadequate.

\section{Conclusions}

Alloy T22 was exposed to humid air in three different reaction tube materials (alumina, ET45 and quartz glass) and at two different pressures (1 bar and 20 bar) at $500{ }^{\circ} \mathrm{C}$ for 310,690 and $1000 \mathrm{~h}$. A uniform, layered oxide scale consisting of hematite/magnetite/Fe-Cr spinel formed on all samples. Thinner layers formed on the samples exposed at 20 bar. At the gas/oxide interface, hematite platelets formed. Larger platelets formed on the samples exposed in the ET45 tube both at 1 and 20 bar. It was noted that the platelet structure formed in the alumina tube and the quartz glass tube differ; possible causes might be impurities from the tubes. At elevated pressure and in an ET45 tube, an increased Cr content was dissolved in the outer oxide scale, with the highest enrichment of $\mathrm{Cr}$ (2 wt\%) found on the samples exposed at 20 bar and in the ET45 tube for 1000 h. To a certain degree $\mathrm{Cr}$ can be correlated to volatile $\mathrm{Cr}$ species deriving from the ET45 tube.

Acknowledgements The authors are thankful to Ellen Berghof-Hasselbächer and Susann Rudolphi for the metallographic preparation, Daniela Hasenpflug for the oxide layer measurements and Dr. Gerald Schmidt for the EPMA measurements.

Funding Open Access funding enabled and organized by Projekt DEAL.

Open Access This article is licensed under a Creative Commons Attribution 4.0 International License, which permits use, sharing, adaptation, distribution and reproduction in any medium or format, as long as you give appropriate credit to the original author(s) and the source, provide a link to the Creative Commons licence, and indicate if changes were made. The images or other third party material in this article are included in the article's Creative Commons licence, unless indicated otherwise in a credit line to the material. If material is not included in the article's Creative Commons licence and your intended use is not permitted by statutory regulation or exceeds the permitted use, you will need to obtain permission directly from the copyright holder. To view a copy of this licence, visit http://creativecommons.org/licen ses/by/4.0/.

\section{References}

1. S. R. Saunders, M. Monteiro, and F. Rizzo, Progress in Materials Science 53, 775-837 (2008).

2. D. L. Douglass, P. Kofstad, A. Rahmel, and G. C. Wood, Oxidation of Metals 45, 529-620 (1996). 
3. J. Ehlers, D. J. Young, E. J. Smaardijk, et al., Corrosion Science 48, 3428-3454 (2006).

4. N. Bertrand, C. Desgranges, D. Poquillon, M. C. Lafont, and D. Monceau, Oxidation of Metals 73, 139-162 (2010).

5. G. M. Raynaud and R. A. Rapp, Oxidation of Metals 21, 89-102 (1984).

6. F. Budiman, N. Bashirom, W. K. Tan, K. A. Razak, A. Matsuda, and Z. Lockman, Applied Surface Science 380, 172-177 (2016).

7. P. J. Meschter, E. J. Opila, and N. S. Jacobson, Annual Review of Materials Research 43, 559-588 (2013).

8. B. Rammer and M. C. Galetz, Werkstoffe und Korrosion 68, 186-196 (2017).

9. M. C. Galetz, B. Rammer, and M. Schütze, Werkstoffe und Korrosion 66, 1206-1214 (2015).

10. N. Birks and F. S. Pettit, Materials Science and Engineering A 143, 187-196 (1991).

11. E. Opila, Journal of the American Ceramic Society 78, 1107-1110 (1995).

12. F. J. Pérez-Trujillo and S. I. Castaneda, Oxidation of Metals 66, 231-251 (2006).

13. D. J. Young and B. A. Pint, Oxidation of Metals 66, 137-153 (2006).

14. S. Madloch, A. Soleimani-Dorcheh, and M. C. Galetz, Oxidation of Metals 89, 483-498 (2017).

15. J. Hagen, Technische Katalyse - Eine Einführung, (Wiley-VCH, Weinheim, 1996).

16. T. D. Reynolds, M. P. Taylor, D. J. Child, and H. E. Evans, Materials at High Temperatures 35, 130-140 (2018).

17. G. R. Holcomb, Ö. N. Dogan, C. Carney, K. Rozman, J. A. Hawk, and M. P. Anderson, The 5th International Symposium - Supercritical CO2 Power Cycles, (San Antonio, Texas, 2016).

18. B. A. Pint, R. G. Brese, and J. R. Keiser, The 5th International Symposium - Supercritical CO2 Power Cycles, (San Antonio, Texas, 2016).

19. F. Rouillard, 8th International Symposium on High-Temperature Corrosion and Protection of Materials (2012).

20. L. Martinelli, C. Desgranges, F. Rouillard, K. Ginestar, M. Tabarant, and K. Rousseau, Corrosion Science 100, 253-266 (2015).

21. R. P. Oleksak, J. H. Tylczak, C. S. Carney, G. R. Holcomb, and Ö. N. Doğan, JOM 70, 1527-1534 (2018).

22. K. Natesan and Z. Zeng, Development of Materials Resistant to Metal Dusting Degradation (U.S. Department of Energy, 2006).

23. M. Scheefer, R. Knödler, B. Scarlin, A. A. Bruna, and D. N. Tsipas, Werkstoffe und Korrosion 56, 907-915 (2005).

24. G. R. Holcomb, Oxidation of Metals 82, 271-295 (2014).

25. I. G. Wright, M. Schütze, P. F. Tortorelli, and R. B. Dooley, Materials at High Temperatures 24, 265-274 (2007).

26. S. Osgerby and A. Fry, Materials Research 7, 141-145 (2004).

27. A. Agüero, V. Gonzalez, M. Gutiérrez, R. Knödler, R. Muelas, and S. Straub, Werkstoffe und Korrosion 62, 561-568 (2011).

28. Y. Otoguro, M. Sakakibara, T. Saito, H. Ito, and Y. Inoue, ISIJ International 28, 761-768 (1988).

29. T. Cheng and P. F. Tortorelli, Journal of the American Ceramic Society 96, 2330-2337 (2013).

30. K. A. Terrani, B. A. Pint, C. M. Parish, C. M. Silva, L. L. Snead, and Y. Katoh, Journal of the American Ceramic Society 97, 2331-2352 (2014).

31. C. Boulesteix, V. Kolarik, and F. Pedraza, Corrosion Science 144, 328-338 (2018).

32. H. Mehrer, $D D F$ 129-130, 57-74 (1996).

33. M. Montgomery and A. Karlsson, VGB Kraftswerkstechnik 75, 235-240 (1995).

34. I. G. Wright and R. B. Dooley, International Materials Reviews 55, 129-167 (2010).

35. K. F. McCarty and D. R. Boehme, Journal of Solid State Chemistry 79, 19-27 (1989).

36. T. Ohtsuka, K. Kubo, and N. Sato, Corrosion 42, 476-481 (1986).

37. M. Schütze, M. Schorr, D. P. Renusch, A. Donchev, and J. P. Vossen, Materials Research 7, 111123 (2004).

38. D. J. Young (ed.), High Temperature Oxidation and Corrosion of Metals, (Elsevier, Amsterdam, 2016).

39. A. Rahmel and J. Tobolski, Corrosion Science 5, 333-346 (1965).

40. J. Zurek, M. Michalik, F. Schmitz, U. Kern, L. Singheiser, and W. J. Quadakkers, Oxidation of Metals 63, 401-422 (2005).

41. K. Segerdahl, J.-E. Svensson, and L.-G. Johansson, Werkstoffe und Korrosion 53, 479-485 (2002).

42. G. R. Holcomb, Oxidation of Metals 69, 163-180 (2008). 
43. C. Key, J. Eziashi, J. Froitzheim, R. Amendola, R. Smith, and P. Gannon, Journal of the Electrochemical Society 161, C373-C381 (2014).

44. L. Zhou, J. H. Mason, W. Li, and X. Liu, Renewable and Sustainable Energy Reviews 134, 110320 (2020).

45. C. M. Harrison, P. R. Slater, and R. Steinberger-Wilckens, Solid State Ionics 354, 115410 (2020).

Publisher's Note Springer Nature remains neutral with regard to jurisdictional claims in published maps and institutional affiliations. 